
\title{
25 Research Soure \\ Laser Surface Texturing and Characterization of Austenitic Stainless Steel for the Improvement of Its Surface Properties
}

Yassmin Seid Ahmed ( $\nabla$ yassminm66@gmail.com )

McMaster University Faculty of Engineering

Jose Mario Paiva

McMaster University Faculty of Engineering

Fred L. Amorim

PUCPR, Mechanical Engineering Graduate Program - PPGEM, R. Imaculada Conceição

Ricardo D. Torres

PUCPR, Mechanical Engineering Graduate Program - PPGEM, R. Imaculada Conceição

Wagner de Rossi

Institute for Energy and Nuclear Research - IPEN Lasers and Applications Center Av. Lineu Prestes 2,242, Cid. University

\section{S.C. Veldhuis}

McMaster Manufacturing Research Institute (MMRI), Department of Mechanical Engineering, McMaster University

\section{Research Article}

Keywords: Surface texturing, AISI 304,Tribological properties, Friction, Wear

Posted Date: March 17th, 2021

DOl: https://doi.org/10.21203/rs.3.rs-293468/v1

License: (9) (1) This work is licensed under a Creative Commons Attribution 4.0 International License. Read Full License 


\section{Abstract}

A detailed investigation of laser textured surfaces produced on austenitic stainless steel (AISI 304) was carried out. Three different textures were produced by a Ti sapphire laser. The processed surfaces were characterized by surface morphology, phase structure, micro-hardness, surface roughness, and wettability. A ball-on-disk tribometer was used to study the tribological performance of both untextured and textured samples. The experimental observations demonstrate that laser surface texturing (LST) improves both surface wettability and surface roughness. Average surface roughness (Ra) was increased by $350 \%$ and the contact angle was reduced from $43^{\circ}$ to $22^{\circ}$. The textured surfaces show a lower coefficient of friction and better wear resistance than the untextured surface. Out of the investigated patterns, the square textures exhibited a maximum reduction of $68 \%$ in the friction coefficient and a $50 \%$ lower wear rate.

\section{Introduction}

Austenitic stainless steels (ASS) see widespread industrial use due to their excellent corrosion resistance, high mechanical properties, and acceptable weldability [1]. They can be used in different applications such as in medical instruments, aerospace products, and chemical manufacturing [1,2]. However, ASS has low thermal conductivity, high work hardening, and low wear resistance [1-4]. Many attempts have been undertaken to enhance the tribological properties of ASS. One of the most promising techniques for enhancing tribological performance is the surface engineering method, such as film deposition [5] and surface texturing [6].

Surface texturing can have a significant effect on the tribological properties of contact surfaces: it can increase the wear resistance and minimize the friction of surfaces. In literature, many methods have been implemented to create different textures, such as abrasive water jet machining [7] and shot peening [8]. Unfortunately, these methods are costly and are not easy to design textures with different sizes. Thus, laser surface texturing (LST) has been used as a unique method that can fabricate different surface patterns with reasonable cost [9-11]. These patterns can enhance the tribological performance by creating thin lubrication films in the contact zone between the sliding surfaces.[12,13]. Besides, the textures can be used to entrap the wear debris between the contact surfaces $[9,10,14-16]$.

Several scientists have carried out several studies on the tribological properties of different textures' shapes using experimental methodologies under several conditions. The conclusion made by these experiments has yielded varying inferences. For example, Rapoport [17] created various textures on stainless steel surfaces using a laser system. The author found that LST generates a bulge, which can prevent the rapid wear-out of surface texture. However, due to the laser's thermal effect, a large amount of molten material and residual thermal stress may lead to microcracks on the machined surface. Rosenkranz et al. [18] investigated the effect of laser textured samples on tribological behavior under dry sliding conditions. Experimental results exhibited a lower coefficient of friction compared to the 
untextured surface. Tang et al. [19] also showed that surface texturing played an important role in minimizing wear rate and friction under sliding contact.

Plenty of efforts was spent on the study to enhance the wear and friction of sliding surfaces. Regardless of the efforts being put in, the tribological performance of ASS after LST has not been studied in detail yet. It requires further exploration. The present study focuses on the friction behavior and wear performance of samples undergoing a ball-on-disc test. The experiments were carried out at room temperature and under dry sliding conditions with different surface texture configurations. The results from three different shapes which include parallel, perpendicular, and square textured surfaces are reported in this research. The textures were fabricated on AISI 304 stainless steel samples using femtosecond laser technology. The influence of these textured surfaces on surface properties was studied in detail using scanning electron microscopy (SEM), an atomic force microscope (AFM) technique, an X-ray diffraction technique (XRD), a white light interferometer, and a microhardness tester.

\section{Materials And Methods}

\subsection{Materials and laser surface texturing}

Four desk specimens made of AISI 304 austenitic stainless steel were used. The dimensions of the samples are $25 \mathrm{~mm}$ in diameter and $5 \mathrm{~mm}$ in thickness. The mechanical properties and chemical compositions of the samples are shown in Table 1. Grit papers were used to obtain a surface finish of 20-60 nm for the specimens. The surfaces of the samples were then laser textured into parallel, perpendicular, and square patterns. Table 2 shows the main features of the textured surfaces.

Ti sapphire femtosecond laser was implemented with a maximum energy of $200 \mu \mathrm{J}$, pulse duration of 30 $\mathrm{fs}$, and frequency of $10 \mathrm{kHz}$ to fabricate different textures on the sample's surface. Once texturing was carried out by the laser beam, the sample was moved through a CNC 3D stage. The energy of the laser pulses was attenuated to a few micro-Joules using a half-wave plate and a polarizer system. The beam was focused on the surface through a focusing lens with a focal length of $20 \mathrm{~mm}$. The piece was moved along with the stage, following the path laid out by the Mastercam CADCAM program.

\subsection{Friction and wear test}

A ball-on-disk tribometer $\left(\mathrm{TRB}^{3}\right)$ was used to perform rotary sliding experiments to estimate the wear performance and friction of the samples. YS8 cemented carbide balls were used in these experiments and the diameter of the ball was $10 \mathrm{~mm}$. Table 3 shows the mechanical properties of the used carbide balls.

Tribological tests were conducted at an applied load of $5 \mathrm{~N}$, a speed of $250 \mathrm{rpm}$, and a sliding time of 20 seconds in a dry environment. The friction experiments were performed under a relative humidity of 30- 
$40 \%$ at $20^{\circ} \mathrm{C}$. Figure 1 presents the schematic diagram of the friction test. The friction test was conducted three times for each sample.

The relation between the coefficient of friction and sliding time can be determined from the results displayed by the TRB ${ }^{3}$ ball-on-disk tribometer's software. The main purpose of this methodology was to be able to calculate the friction coefficients' average from the values gained from the stage related to the stable curve. Equation (1) was used to obtain the wear rate value of each textured sample [9].

Wear rate $=\frac{A \times\left(D-W \frac{D}{P}\right)}{F \times L}$

where $A$ and $D$ are the area $\left(\mu \mathrm{m}^{2}\right)$, and length $(\mathrm{mm})$ of the wear scar, respectively. $W$ and $P$ are the channel width $(\mu \mathrm{m})$ and pitch $(\mu \mathrm{m})$, respectively. $F$ is the normal load $(N)$ and $L$ is the sliding length $(\mathrm{m})$.

\subsection{Analysis and characterization}

Following friction and wear tests, topographies of the patterns were observed in an optical microscope (VHX-2000, Keyence) together with a scanning electron microscope (SEM Vega 3-TESCAN). Furthermore, the profiles and the three-dimensional (3D) topographies' surfaces of the wear scars were measured by a white light interferometer (Alicona infinite focus G5 microscope) and an atomic force microscope (AFM TOSCATM 400). The distribution of elements on the wear scar was evaluated by an energy dispersive spectrometer (EDS). The micro-hardness of the textured surfaces was measured using a microhardness tester with an applied load of $0.05 \mathrm{kgf}$ for $20 \mathrm{~s}$.

\subsection{Contact angle measurements}

Wettability measurements were taken under static contact angles using the sessile drop method. A goniometer was used with $6 \mu \mathrm{L}$ droplets of coolant dispensed on the sample surfaces. Five contact angle measurements were made at $23^{\circ} \mathrm{C}$ and relative humidity of between $30 \%$ and $50 \%$. The mean average of the static contact angle from these 5 measurements was then recorded as the mean contact angle. The measurement method consisted of an apparent contact angle that measured each frame of the droplet that lasted for 60 seconds. To obtain more precise measurements of the contact angle variations, the videos ran at about 10 frames per second. Once the droplets reached an equilibrium state, the contact angle was picked up. This means that the droplets steadily remained on the surface before any evaporation took place. This kind of state lasted for 10 seconds following droplet deposition. A drop shape analysis was used to calculate the contact angles.

\section{Results And Discussions}


The morphology of the textures will be presented first to fully characterize the laser surface texture patterns' dimensions and properties. Results of the dry sliding friction test and the wear properties of the textured samples will be then presented, enabling comparisons to be made between smooth and textured samples through output variables.

\subsection{Examination of laser textured samples}

\subsubsection{Morphology and characterization}

Figure 2 shows the representative two-dimensional (2D) white light interferometry images and optical micrographs of both polished and textured surfaces. The polished surface is shown in Fig. 2a. Figure 2 (b-e) shows the square, parallel and perpendicular textures, respectively. According to the results found, the surface textures analyzed are arranged regularly and there are no defects on the surface.

Figure 3 (a-c) and Fig. 3 (d-f) show the 3D surface topographies and the sectional profile of the textures, respectively. As shown, the dimensions of the channels are $5 \pm 0.2 \mu \mathrm{m}$ width, $20 \pm 0.3 \mu \mathrm{m}$ pitch, and $1.5 \pm$ $1 \mu \mathrm{m}$ depth. The high changes in depth are because of the existence of carbide particles in the samples. This caused variations in the laser beam during the manufacturing operation.

Figure $4(a, b)$ shows the 2D and 3D micrographs of a single micro-groove, respectively. The results observed the absence of re-solidified particles that are substantial enough. Additionally, the area surrounding the micro-groove relating to the zone that is affected by heat is narrow. The observation above is easily explainable using the fact that surfaces related to AISI 304 are vaporized directly by femtosecond laser especially during ablation. Since pulses of femtosecond laser have extremely short time scales, it is easy to see why consideration of the process of ablation as a solid-vapor transition is feasible [20].

Figure 5 displays the comparison of surface roughness for the smooth and textured surfaces. The Ra and $\mathrm{Rz}$ of the smooth surface were about $20 \mathrm{~nm}$ and $26 \mathrm{~nm}$, respectively. As shown, surface roughness increased following the laser texturing process due to the existence of a textured surface. In surfaces with parallel and perpendicular patterns, the increase of these two values $(\mathrm{Ra}, \mathrm{Rz})$ was lesser than in the square textured one, whose Ra was $350 \%$ and $\mathrm{Rz}$ was 1.8 greater than those of the untextured surface.

\subsubsection{Wettability analysis}

Figure 6 shows the contact angles of the coolant droplets resting on untextured and textured surfaces where the hydrophilic nature of the initial polished untextured surface with a contact angle of $43.5^{\circ}$ is noticed. The contact angle marginally decreases after laser treatment: $23.2^{\circ}$ in the perpendicular textured surface, $22.8^{\circ}$ in the parallel textured surface, and $22.2^{\circ}$ in the square textured surface. This confirms the ability of laser surface texturing (LST) to improve the wettability of the surfaces. Results also indicate a 
greater decrease of contact angle in all textured surfaces. This because of the presence of the grooves which lead to an increase in the average surface roughness, as can be seen in Fig. 5.

The increase of surface roughness enables greater interaction of the sample with the drop. This causes a reduction in the contact angles by increasing the droplet diameter and reducing the height. In the meantime, there is a slight variation in contact angle values between parallel and perpendicular textured samples (Fig. 6) since the surface roughness values remain almost the same (Fig. 5).

\subsubsection{Phase structure analysis and micro-hardness measurements}

Apart from the topographic changes induced by the laser treatment, it is well known that its thermal effect can also alter the surface's microstructure [20]. Because LST is a high-energy technique, it can induce phase transitions on the surface of the samples. Thus, XRD was performed on both smooth and textured samples to analyze these changes. Figure 7 presents a set of typical XRD patterns of the original and textured samples. It is known that the microstructure of the original surface is austenite and by taking a closer look at the XRD pattern, there is a confirmation that there is a presence of the austenite $(\mathrm{Y})$ phase only. After conducting an LST, there is a lack of evidence supporting the presence of ferrite precipitates or phase from the profile gained from diffraction. These results confirm that LST does not affect the phase transformation of textured samples.

Figure 8a presents the optical images of the indentations close to the channels as well as the corresponding hardness values. Figure $8 \mathrm{~b}$ shows the changes in hardness values as a function of the distance from the channels and as shown the hardness values close to the channels are lower compared with the hardness of the surface after LST. For square textures, the hardness is $490 \mathrm{HV}$ at a distance of $15 \mu \mathrm{m}$ from the channel edge, which is $30 \%$ less than its original hardness. The hardness decreases by a much lower amount in parallel and perpendicular textured surfaces at the same distance, about $26 \%$ and $20 \%$ less than the original sample.

\subsection{Friction properties of the laser textured sample}

The results of ball-on-disc tests showed a considerable decrease in the coefficient of friction (COF) for textured samples compared to the smooth specimen. Figure 9 depicts the relationship between the COF and the sliding time. As shown, a sudden increase in the COF was noticed in all test samples at the initial stage It gradually became stable after 10 seconds of sliding. This stable period was used to evaluate the $\mathrm{COF}$ of all test samples. Areas of severe deformation are produced by the action of entrapped wear debris at the sliding interface. Thus, minor fluctuations in the COF were indicated for all textured surfaces. Under the dry sliding condition, the smooth surface had a COF of 0.22 whereas that of the perpendicular and parallel textured specimens had COFs of 0.13 and 0.14 , respectively. An even better result was obtained in the square textured surfaces, where the COF was found to be 0.07 . 
The smooth surface's higher COF can be attributed to the higher material interactions at the microscopic level. Conversely, in textured surfaces, the reduction of the contact area improves the sliding performance and mitigates friction. The smaller contact area of the textured surfaces also accounts for their lower COF during all tribological tests. Usually, deformation mechanisms and adhesion that occur at microscopic levels are truly the predominant factors that influence dry friction. On one hand, deformation takes place because of the interlocking caused by micro asperities due to the applied load. On the other hand, adhesion is a result of the bonding that takes place between the surfaces that slide with each other. Therefore, an added level of force needs to be used when sliding occurs to make sure that the force components of both deformation and force are dealt with. Moreover, studies have shown that the additional force leads to the generation of wear particles that occur on the contact interface that usually act as an additional body that interacts with the surfaces sliding, which in that case causes the growth of friction even more. The force of deformation and adhesion are more pronounced in smooth surfaces because they have a higher rate of sliding and sticking due to the two forces occurring at the smallest level. However, the study found out that the reduction in contact length especially in the surfaces that are textured, the less the generation of frictional force by the relative motion that will occur.

Furthermore, the study found out that wear debris' entrapment that is done by the channels had a considerable reduction in COF. This is due to the further elimination of the abrasion of particles that were entrapped in between the surfaces that were sliding against each other. This was proved by the results where COF was reduced by $36 \%$ and $40 \%$ for perpendicular and parallel specimens, respectively. An even better COF reduction of $68 \%$ was observed in the square textured sample.

Figure 10 presents the EDS results of different spots: spot A between the grooves, spot $B$ inside the groove, and spot $C$ at the worn surfaces. Spot $A$ contained a high amount of oxygen compared to the original surface, which means that oxidation had happened at the surface. This is beneficial as the oxidation can be used to minimize the contact between the cutting tool and the chip, which helps reduce the COF [21]. Also, the amount of Fe at spot $C$ is lower than that at spot B, which indicates that the textures can trap wear debris. Conversely, on the smooth surface, the COF rapidly grows due to the lack of such a capability. The smaller contact area of the textured surfaces also reduces the resistance during the sliding process [9].

\subsection{Wear properties of the laser textured samples}

The calculated wear rates of the polished and textured samples are shown in Fig. 11. The graph showcases the optimal anti-wear properties of the square textured surface, whose wear rate is the lowest of all tested samples (the highest was that of the smooth surface). The wear rate values accord with the variations in average friction coefficients, demonstrating the wear resistance improvement that can be achieved by femtosecond LST. The textured samples exhibit a high wear resistance due to the combination of debris entrapment and lower contact surface. Thus, variation in the wear rates and average $\mathrm{COF}$ are similar. 
Optical images of the worn surfaces of the polished and textured surfaces are shown in Fig. 12. As shown, wear scars were formed for all surfaces due to the mechanical rubbing between the ball and the samples. On the smooth surface, intense scratches and adhesions are visible on the wear surface (Fig. 12a). In the textured samples, the channels can be seen clearly on the wear sample and they are covered with wear debris (Fig. 12 (b-d)).

Figures (13-16) show the scratches and adhesion on the respective worn surfaces of the untextured, perpendicular, parallel, and square textured samples. Figure 13(a,b) shows the adhesion of the material to the untextured surface. Deep marks and adhesion are visible on the surface due to a combination of abrasive and adhesive wear [13,22-24]. For the untextured surface, it is difficult to reserve debris. Debris generated by friction can impact the untextured surface, thereby causing abrasive wear as confirmed by EDS analysis of point A in Fig. 13c.

However, Figs. (14-16) indicate that the worn areas are smoother with no evidence of furrowing lines on the patterns. The channels collect small wear particles, thereby preventing them from making furrows on the worn surface $[11,21]$. SEM images of worn areas and EDS analysis at point $B$ of all textured samples revealed that wear debris fills most of the texture channels. EDS analyses also show that point $A$ has a lower amount of $\mathrm{W}$ compared to point $\mathrm{B}$.

Figure 17 (a-d) presents the cross-sectional profiles of different wear scars. These profiles are measured on untextured and textured surfaces using the Alicona microscope. The wear scar on the textured surfaces has a lower depth than those on the untextured sample. The square textured surface has the shallowest wear scar compared to other surfaces, demonstrating the improvement of wear resistance achieved by femtosecond laser applied textures.

\section{Conclusions}

This study examines laser surface texturing (LST) of austenitic stainless steel (AISI 304) samples with three different texture shapes using a Ti: sapphire laser. The textured samples were characterized in detail. Wear and friction tests were performed using the ball-on-disk experiments under dry conditions. The key findings from this investigation can be reported as the following:

1. Laser-assisted periodic textured patterns were applied to stainless steel samples in the square, parallel, and perpendicular shapes. The more hydrophilic surface was obtained after LST reached approximately $22.2^{\circ}, 22.8^{\circ}, 23.2^{\circ}$ when the stainless steel sample was textured into the respective square, parallel, and perpendicular shapes.

2. The femtosecond LST exhibited a marked potential to minimize the wear rate and coefficient of friction (COF). Textured surfaces showed a relative reduction in COF compared to the polished surfaces. Net COF reductions of $36 \%, 40 \%$, and $68 \%$ were obtained by perpendicular, parallel, and square patterns, respectively. The wear rate of perpendicular, parallel, and square samples was respectively reduced by about $22 \%, 37 \%$, and $50 \%$ compared to the smooth surface. 
3. The adhesion and wear debris on the wear scars of the textured samples were milder compared to those of the smooth samples. Meanwhile, the wear depth was decreased in the parallel and square textured samples, with the latter exhibiting the lowest wear depth.

\section{Declarations}

\section{Acknowledgment}

This research was supported by the Natural Sciences and Engineering Research Council of Canada (NSERC) under the CANRIMT Strategic Research Network Grant NETGP 479639-15.

\section{Author information}

\section{Affiliations}

McMaster Manufacturing Research Institute (MMRI), Department of Mechanical Engineering, McMaster University, 1280 Main Street West, Hamilton, ON L8S4L7, Canada

Yassmin Seid Ahmed, Jose Mario Paiva, S.C. Veldhuis

Production Engineering Department, Alexandria University, Alexandria, 21544, Egypt

Yassmin Seid Ahmed

PUCPR, Mechanical Engineering Graduate Program - PPGEM, R. Imaculada Conceição, 1155 - Prado Velho, Curitiba 80215 901, Brazil

Jose Mario Paiva, Fred L. Amorim, Ricardo D. Torres,

Institute for Energy and Nuclear Research - IPEN Lasers and Applications Center Av. Lineu Prestes 2,242, Cid. University - CEP 05508-000 São Paulo, SP

Wagner de Rossi

\section{Contributions}

Yassmin Seid Ahmed performed the cutting experiments as well as metallographic, AFM, SEM, EBSD, XRD analyses, nanohardness test, planned experimental procedures and wrote the paper. Jose Mario Paiva reviewed the manuscript. Fred Amorim, Ricardo Torres and Wagner de Rossi applied LST on the cutting tools. Stephen Clarence Veldhuis was the supervisor of the research team.

Corresponding author

Correspondence to Yassmin Seid Ahmed.

\section{Competing interests}


The authors declare that they have no competing interests.

\section{Ethical approval}

Not applicable.

\section{Consent to participate}

Not applicable.

\section{Consent to publish}

Not applicable.

\section{Funding}

Not applicable.

\section{Availability of data and materials}

Not applicable.

\section{References}

1. S. Bruschi, L. Pezzato, A. Ghiotti, M. Dabalà, R. Bertolini, Effectiveness of using low-temperature coolants in machining to enhance durability of AISI 316L stainless steel for reusable biomedical devices, J. Manuf. Process. 39 (2019) 295-304. doi:10.1016/j.jmapro.2019.02.003.

2. P. Hoier, A. Malakizadi, S. Friebe, U. Klement, P. Krajnik, Microstructural variations in $316 \mathrm{~L}$ austenitic stainless steel and their influence on tool wear in machining, Wear. 428-429 (2019) 315-327. doi:10.1016/j.wear.2019.02.024.

3. O. Andreau, I. Koutiri, P. Peyre, J.D. Penot, N. Saintier, E. Pessard, T. De Terris, C. Dupuy, T. Baudin, Texture control of $316 \mathrm{~L}$ parts by modulation of the melt pool morphology in selective laser melting, J. Mater. Process. Technol. 264 (2019) 21-31. doi:10.1016/j.jmatprotec.2018.08.049.

4. J. Fu, J. Sun, X. Cen, X. Zhang, F. Li, Y. Wu, Growth behavior and orientation relationships in AISI 304 stainless steel during directional solidification, Mater. Charact. 139 (2018) 241-248. doi:10.1016/J.MATCHAR.2018.03.015.

5. Y. Seid Ahmed, J. Paiva, D. Covelli, S. Veldhuis, Investigation of Coated Cutting Tool Performance during Machining of Super Duplex Stainless Steels through 3D Wear Evaluations, Coatings. 7 (2017) 127. doi:10.3390/coatings7080127.

6. N. Kawasegi, T. Kawashima, N. Morita, K. Nishimura, M. Yamaguchi, N. Takano, Effect of texture shape on machining performance of textured diamond cutting tool, Precis. Eng. 60 (2019) 21-27. doi:10.1016/j.precisioneng.2019.07.007. 
7. D.K. Singh, V.K. Jain, V. Raghuram, R. Komanduri, Analysis of surface texture generated by a flexible magnetic abrasive brush, Wear. 259 (2005) 1254-1261. doi:10.1016/j.wear.2005.02.030.

8. N. Coniglio, S. Mezghani, M. El Mansori, J. Cabrero, Effect of nano-penning surface texturing on selfcleaning function, Surf. Coatings Technol. 353 (2018) 126-134. doi:10.1016/j.surfcoat.2018.07.103.

9. Z. Wang, Y.B. Li, F. Bai, C.W. Wang, Q.Z. Zhao, Angle-dependent lubricated tribological properties of stainless steel by femtosecond laser surface texturing, Opt. Laser Technol. 81 (2016) 60-66. doi:10.1016/j.optlastec.2016.01.034.

10. Y. Xing, J. Deng, Z. Wu, F. Wu, High friction and low wear properties of laser-textured ceramic surface under dry friction, Opt. Laser Technol. 93 (2017) 24-32. doi:10.1016/J.OPTLASTEC.2017.01.032.

11. L. Lu, Z. Zhang, Y. Guan, H. Zheng, Comparison of the effect of typical patterns on friction and wear properties of chromium alloy prepared by laser surface texturing, Opt. Laser Technol. 106 (2018) 272-279. doi:10.1016/j.optlastec.2018.04.020.

12. Y. Xing, J. Deng, Z. Wu, F. Wu, High friction and low wear properties of laser-textured ceramic surface under dry friction, Opt. Laser Technol. 93 (2017) 24-32. doi:10.1016/j.optlastec.2017.01.032.

13. J. Kümmel, D. Braun, J. Gibmeier, J. Schneider, C. Greiner, V. Schulze, A. Wanner, Study on micro texturing of uncoated cemented carbide cutting tools for wear improvement and built-up edge stabilisation, J. Mater. Process. Technol. 215 (2015) 62-70. doi:10.1016/j.jmatprotec.2014.07.032.

14. K. Zhang, J. Deng, Y. Xing, S. Li, H. Gao, Effect of microscale texture on cutting performance of WC/Co-based TiAIN coated tools under different lubrication conditions, Appl. Surf. Sci. 326 (2015) 107-118. doi:10.1016/j.apsusc.2014.11.059.

15. S. Niketh, G.L. Samuel, Surface texturing for tribology enhancement and its application on drill tool for the sustainable machining of titanium alloy, J. Clean. Prod. 167 (2018) 253-270. doi:10.1016/j.jclepro.2017.08.178.

16. K. Zhang, X. Guo, L. Sun, X. Meng, Y. Xing, Fabrication of coated tool with femtosecond laser pretreatment and its cutting performance in dry machining SLM-produced stainless steel, J. Manuf. Process. 42 (2019) 28-40. doi:10.1016/j.jmapro.2019.04.009.

17. L. Rapoport, A. Moshkovich, V. Perfilyev, I. Lapsker, G. Halperin, Y. Itovich, I. Etsion, Friction and wear of MoS2 films on laser textured steel surfaces, Surf. Coatings Technol. 202 (2008) 3332-3340. doi:10.1016/j.surfcoat.2007.12.009.

18. A. Rosenkranz, H.L. Costa, F. Profito, C. Gachot, S. Medina, D. Dini, Influence of surface texturing on hydrodynamic friction in plane converging bearings - An experimental and numerical approach, Tribol. Int. 134 (2019) 190-204. doi:10.1016/j.triboint.2019.01.042.

19. Genetic Algorithm-Based Optimization of Steam Consumption of Dryer Section in Paper Machine I Scientific.Net, (n.d.). https://www.scientific.net/AMM.472.180 (accessed June 7, 2020).

20. X. Wang, T. Zhou, H. Zhou, P. Wu, M. Ran, Z. Gao, H. Zhou, C. Kong, P. Zhang, Effects of laser on the non-smooth surface in improving the durability of hot forging tools, Opt. Laser Technol. 119 (2019) 105598. doi:10.1016/j.optlastec.2019.105598. 
21. S. Niketh, G.L. Samuel, Drilling performance of micro textured tools under dry, wet and MQL condition, J. Manuf. Process. 32 (2018) 254-268. doi:10.1016/j.jmapro.2018.02.012.

22. D. Vasumathy, A. Meena, Influence of micro scale textured tools on tribological properties at tool-chip interface in turning AISI 316 austenitic stainless steel, Wear. 376-377 (2017) 1747-1758. doi:10.1016/j.wear.2017.01.024.

23. C. Zhou, X. Guo, K. Zhang, L. Cheng, Y. Wu, The coupling effect of micro-groove textures and nanofluids on cutting performance of uncoated cemented carbide tools in milling Ti-6Al-4V, J. Mater. Process. Technol. 271 (2019) 36-45. doi:10.1016/j.jmatprotec.2019.03.021.

24. Z. Wu, Y. Xing, P. Huang, L. Liu, Tribological properties of dimple-textured titanium alloys under dry sliding contact, Surf. Coatings Technol. 309 (2017) 21-28. doi:10.1016/j.surfcoat.2016.11.045.

\section{Tables}

Table 1. Material properties and chemical composition, of AISI 304 stainless steel samples [25].

\begin{tabular}{|c|c|c|c|c|c|c|}
\hline \multicolumn{7}{|c|}{ Material properties } \\
\hline \multirow[t]{2}{*}{$\begin{array}{l}\text { Weight } \\
\%\end{array}$} & $\begin{array}{l}\text { Proof } \\
\text { Strength } \\
\text { (MPa) }\end{array}$ & $\begin{array}{l}\text { Tensile } \\
\text { Strength } \\
\text { (MPa) }\end{array}$ & $\begin{array}{l}\text { Elongation } \\
\text { (\%) }\end{array}$ & $\begin{array}{l}\text { Modulus of } \\
\text { Elasticity (GPa) }\end{array}$ & $\begin{array}{l}\text { Shear } \\
\text { Modulus } \\
\text { (GPa) }\end{array}$ & \\
\hline & & & & & & $\begin{array}{l}\text { Hardness } \\
\text { (HRC) }\end{array}$ \\
\hline 0.08 & 215 & 505 & 70 & 200 & 86 & 70 \\
\hline \multicolumn{7}{|c|}{ Chemical composition (\%) } \\
\hline C & Mn & $\mathbf{P}$ & $S$ & $\mathrm{Cr}$ & $\mathrm{Ni}$ & $\mathbf{N}$ \\
\hline 0.08 & 2.0 & 0.045 & 0.03 & 20.0 & 0.50 & 0.10 \\
\hline
\end{tabular}

Table 2. Parameters of textures main features characteristics of LST specimens.

\begin{tabular}{|llll|}
\hline Specimen & Width $(\mu \mathrm{m})$ & Pitch $(\mu \mathrm{m})$ & Depth $(\mu \mathrm{m})$ \\
\hline Untextured & - & - & - \\
\hline Parallel & 5 & 15 & $2-3$ \\
\hline Perpendicular & 5 & 15 & $2-3$ \\
\hline Square & 5 & 15 & $2-3$ \\
\hline
\end{tabular}

Table 3. Mechanical properties of YS8 cemented carbide balls. 
Density $\left(\mathrm{g} / \mathrm{cm}^{3}\right) \quad$ Bending strength (MPa) Hardness (HRA)

$\begin{array}{lll}13.9 & 1720 & 92.5\end{array}$

Figures

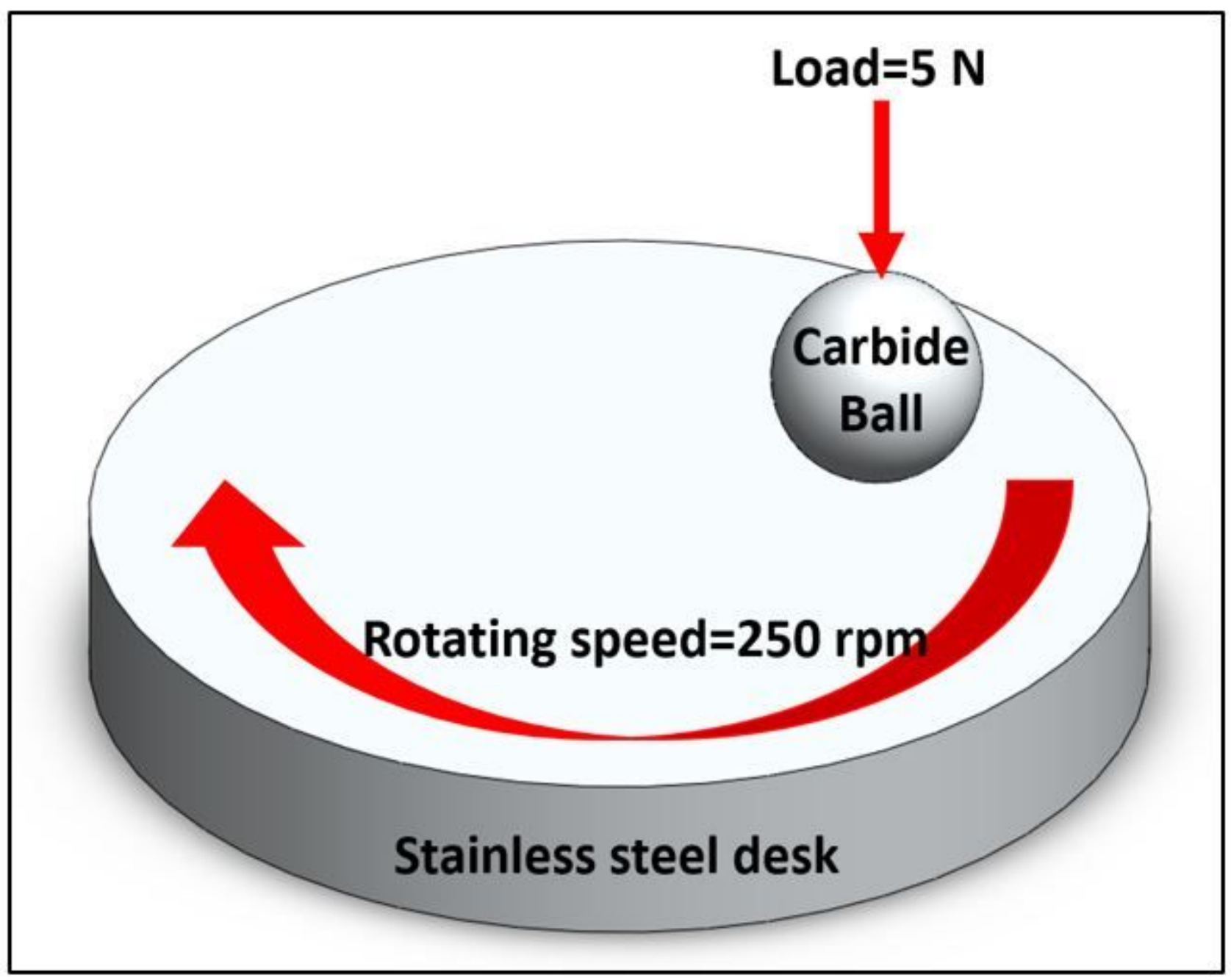

Figure 1

Schematic diagram of the friction and wear test. 


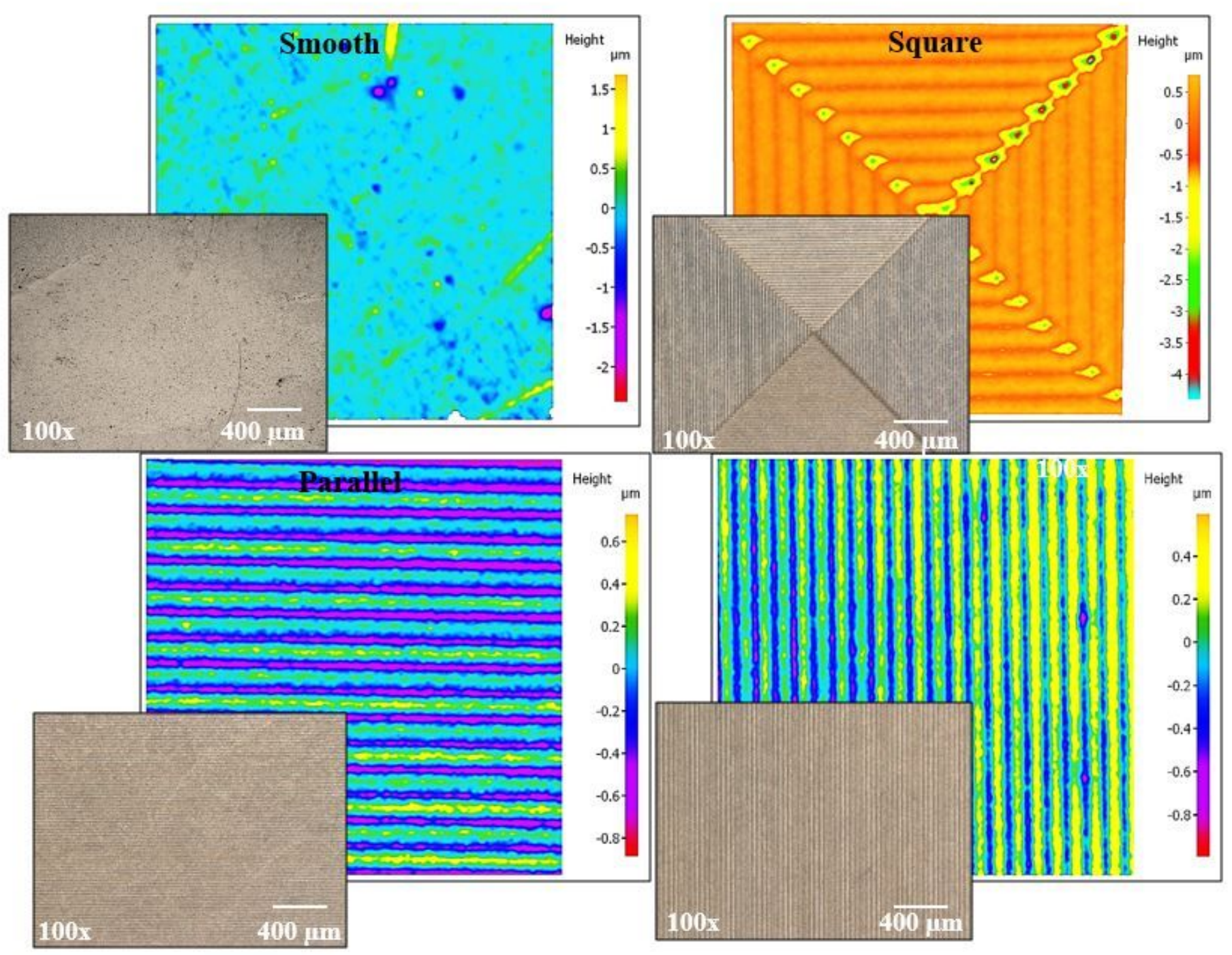

Figure 2

Two-dimensional white light interferometry images as well as optical images of textured surfaces after LST. 


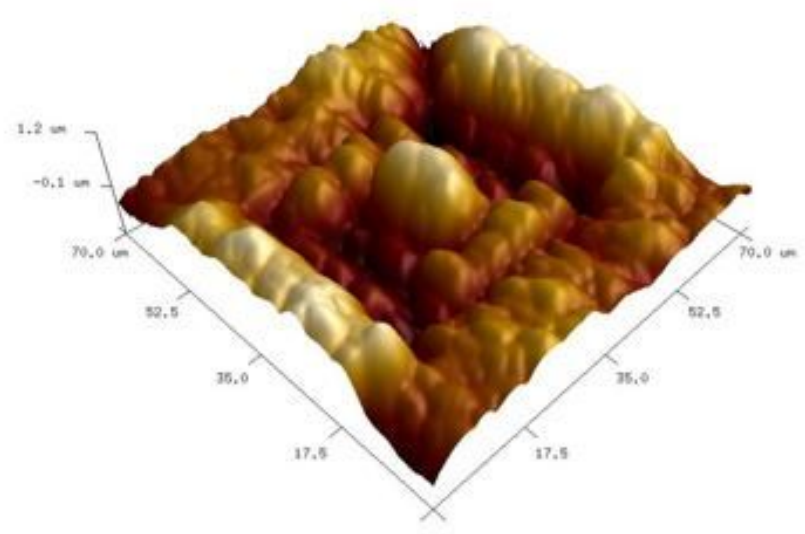

(a)

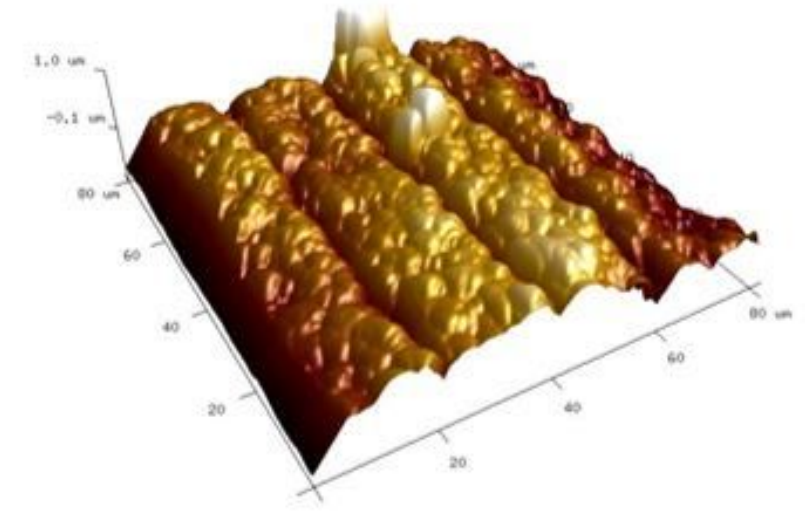

(b)

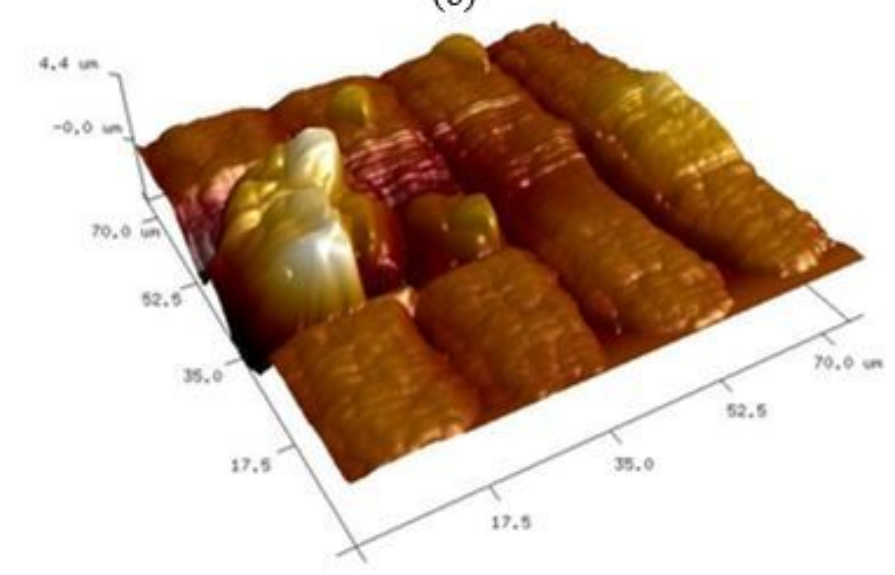

(c)

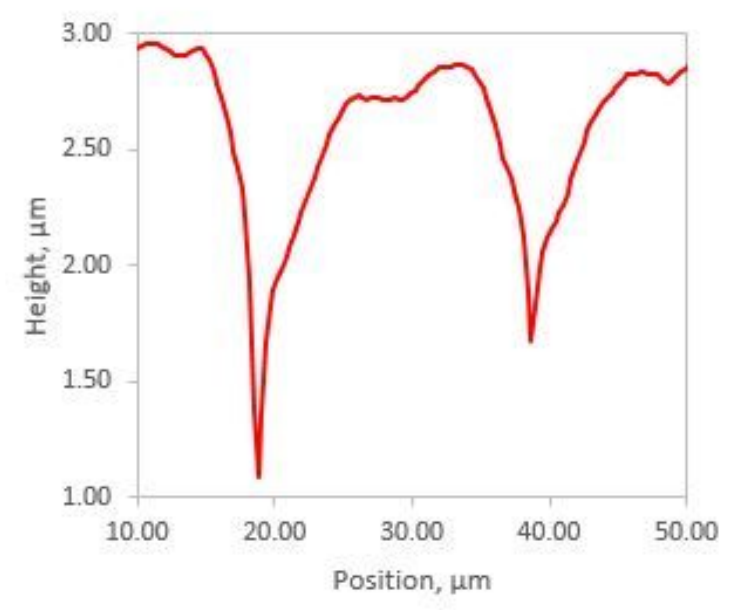

(d)

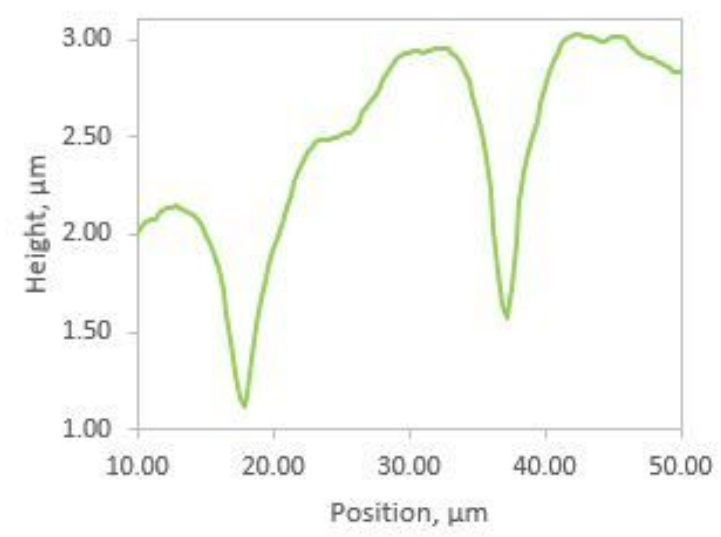

(e)

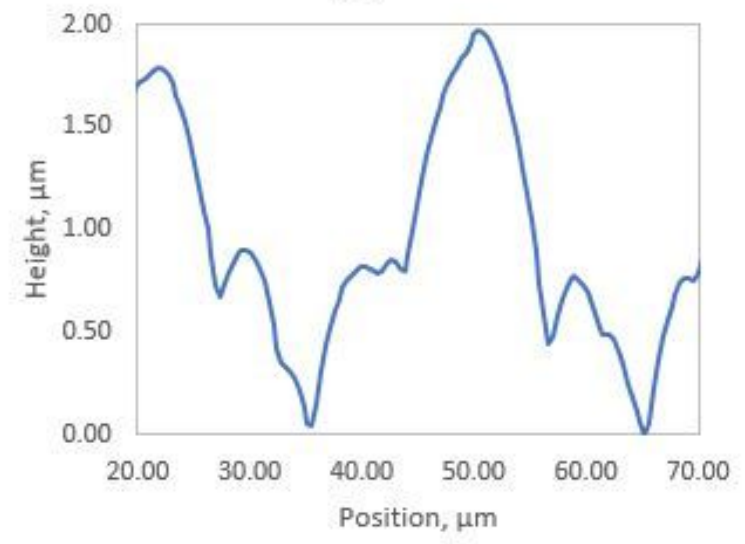

(f)

\section{Figure 3}

(a-c) Atomic force microscope images of surface topography of (a) square, (b) parallel, (c) perpendicular, and (d-f) corresponding two-dimensional profile of different textured surfaces of (a) square, (b) parallel, and (c) perpendicular. 


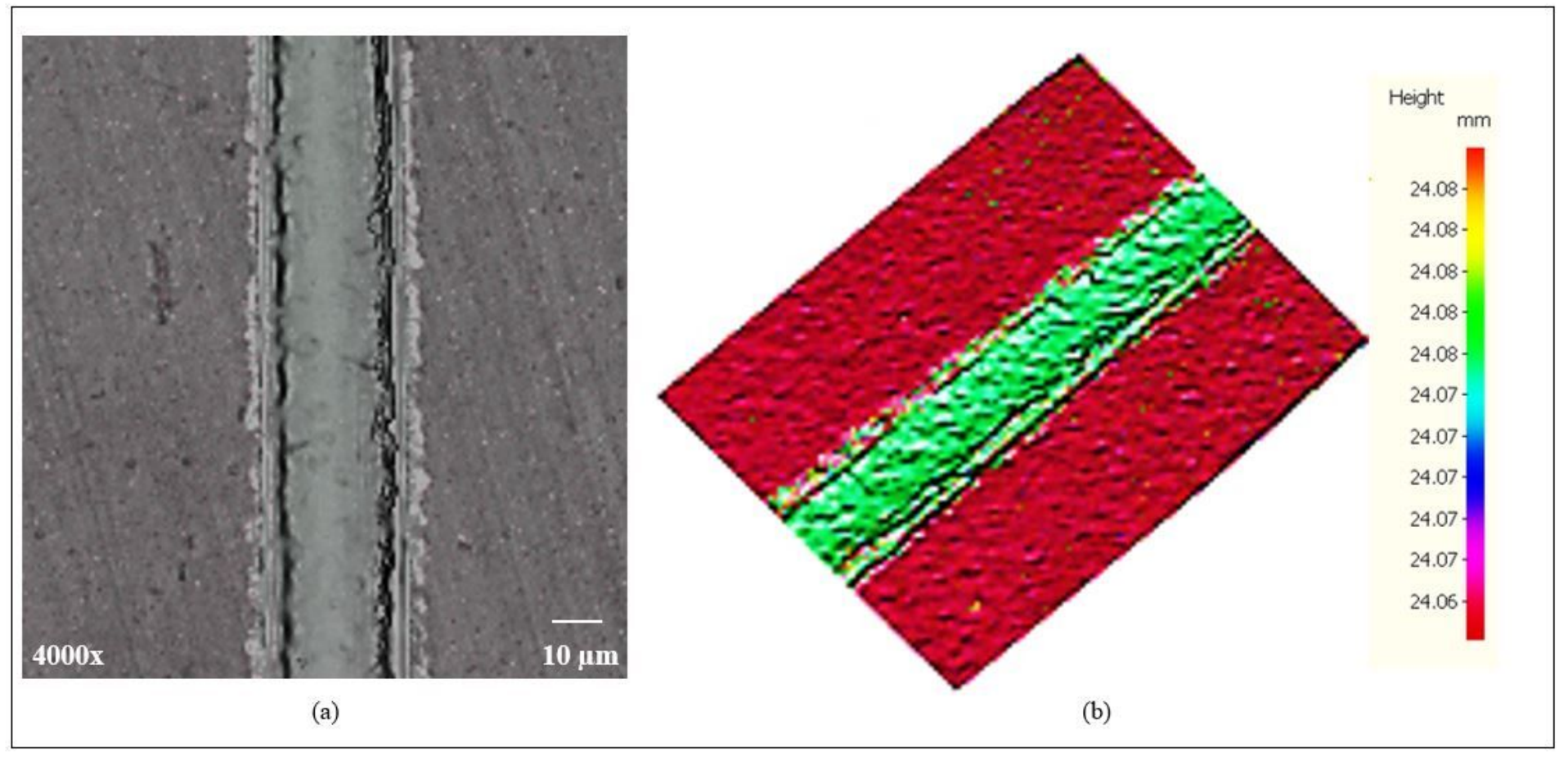

Figure 4

(a) SEM image of a single micro-groove and (b) corresponding surface topography. 


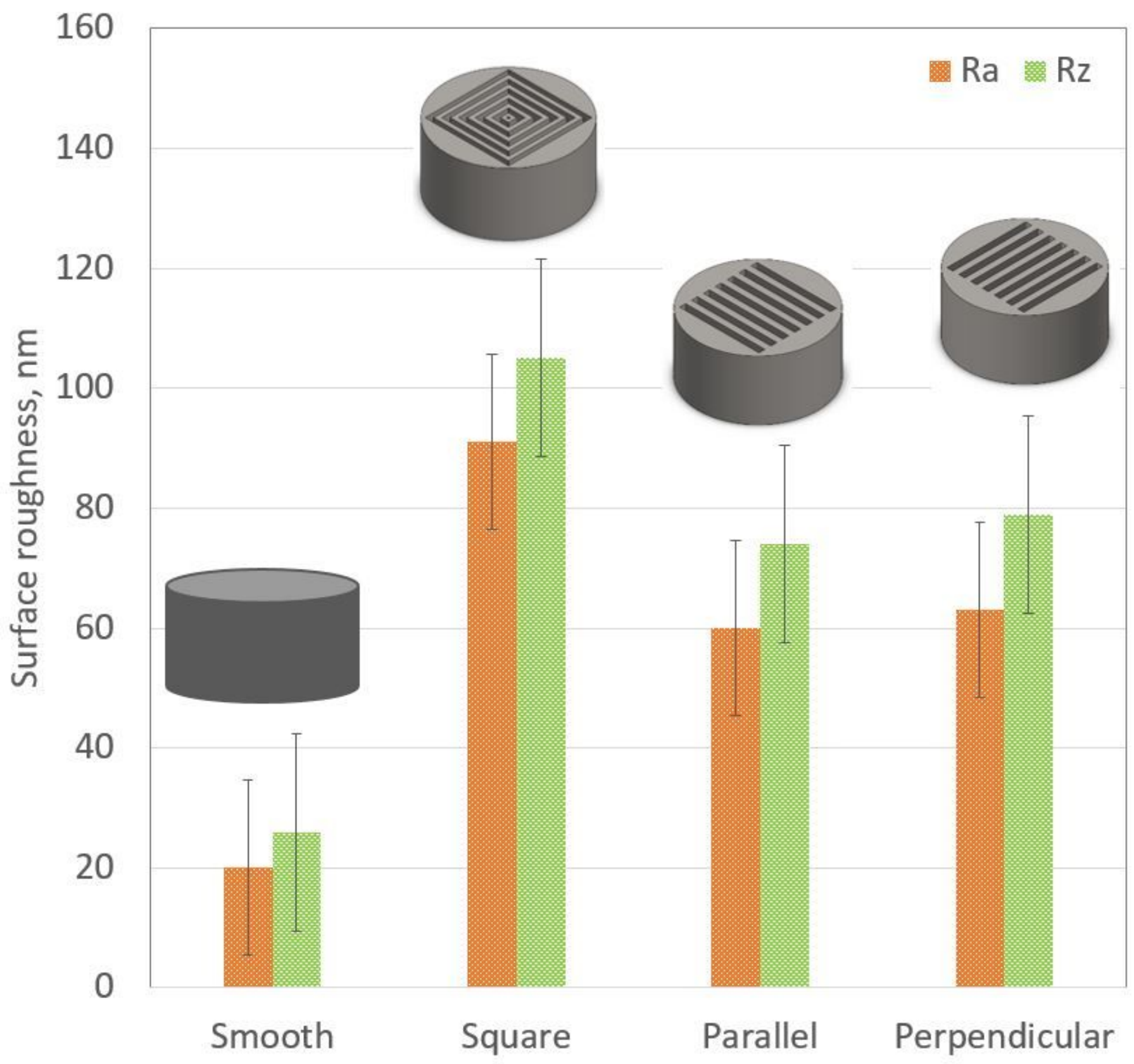

Figure 5

Surface roughness values of different laser textured patterns. 


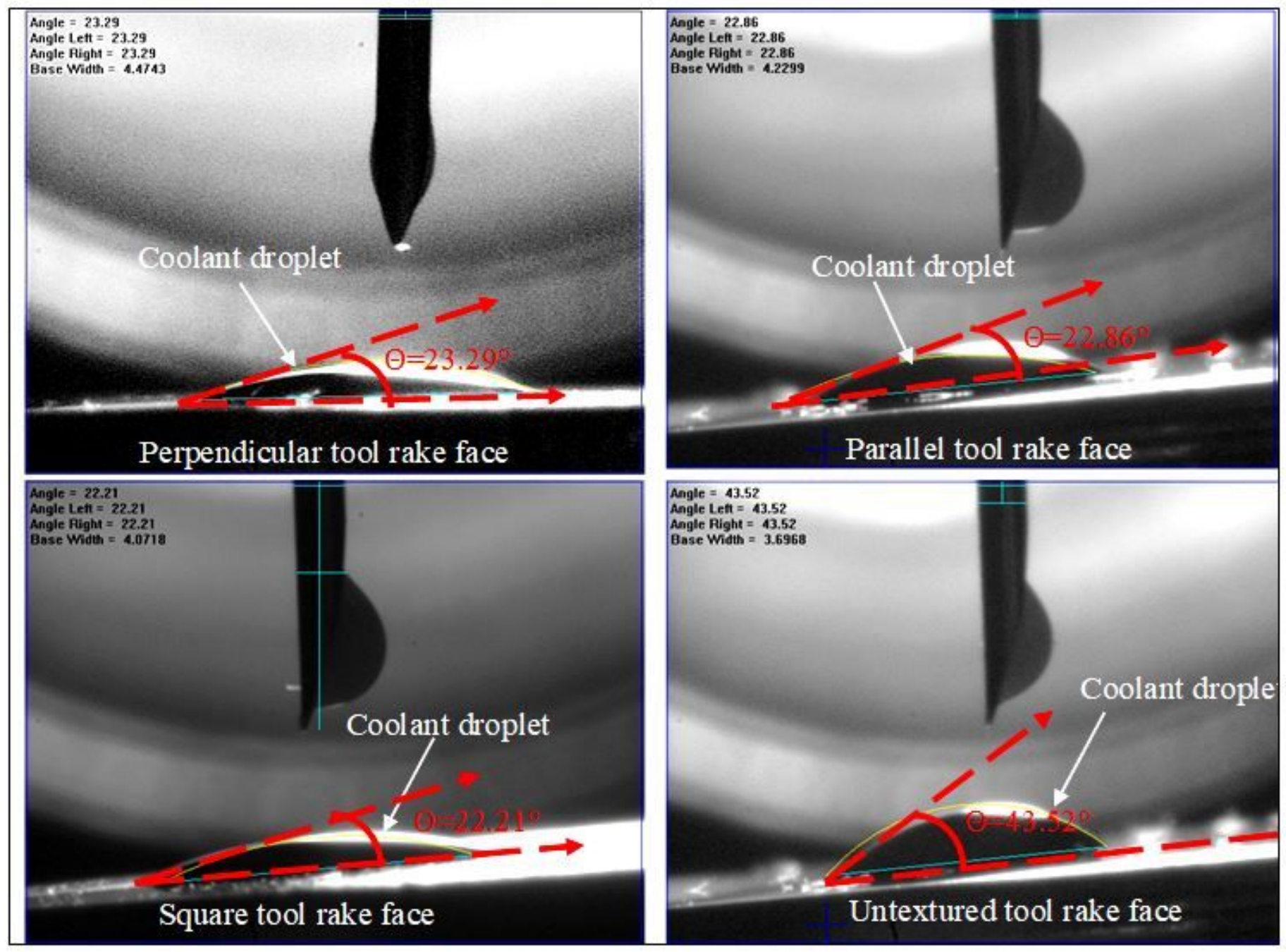

Figure 6

Microscopic side view of coolant droplet resting on the untextured and micro-textured tool rake surfaces, showing the contact angle values. 


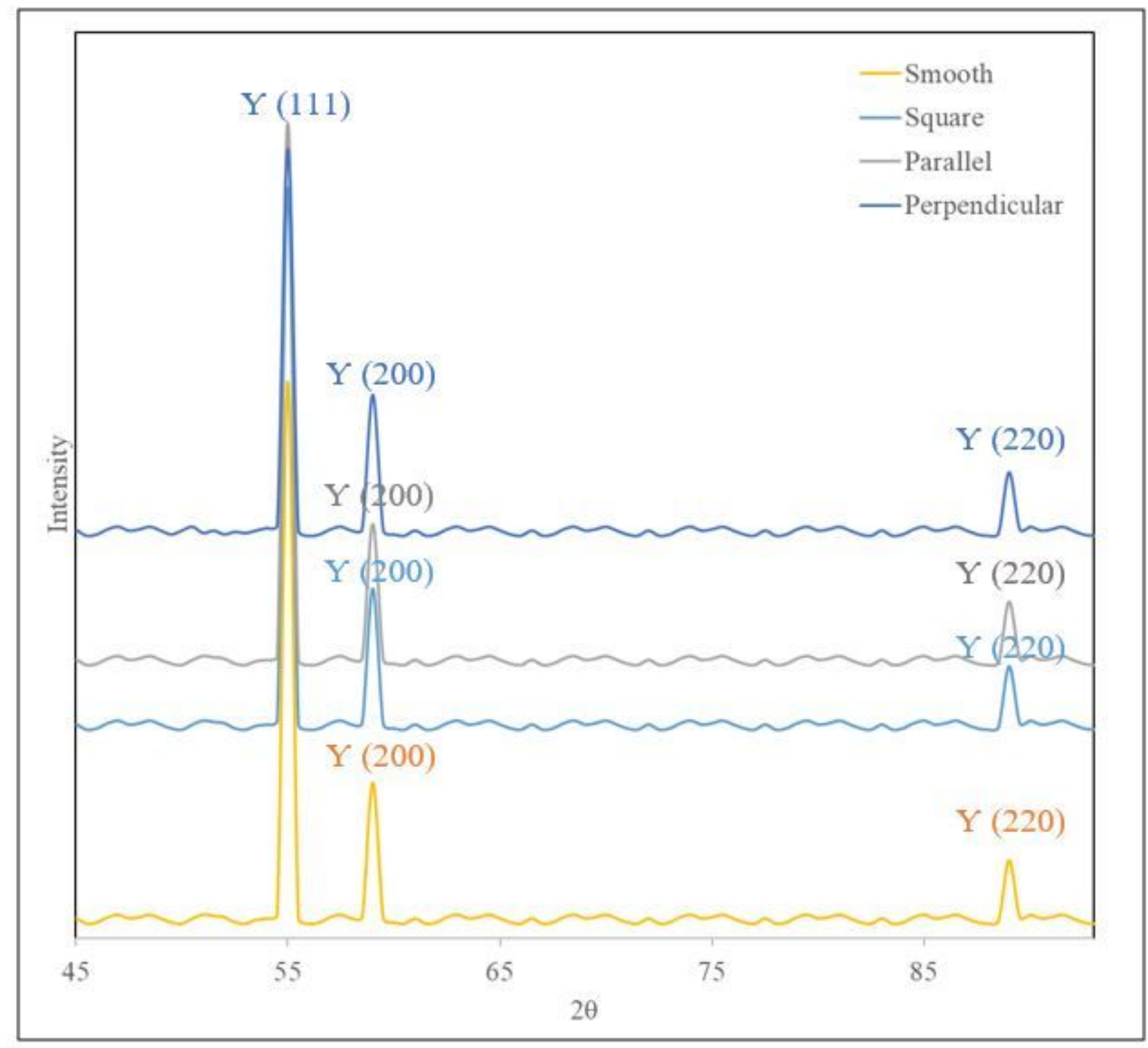

Figure 7

XRD diffractogram analysis for the smooth surface and different textured surfaces. 


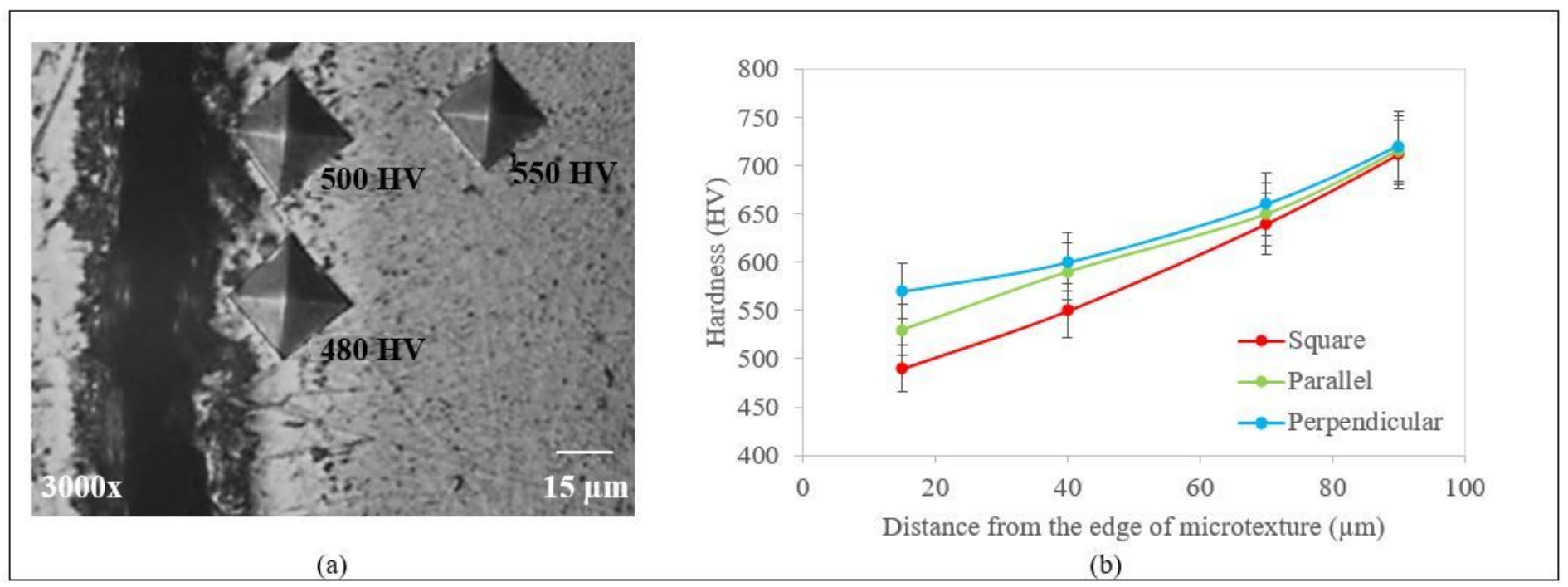

\section{Figure 8}

(a) An example of typical optical micrographs of the Vickers indentations and (b) Vickers hardness values near micro-groove of different textured surfaces.

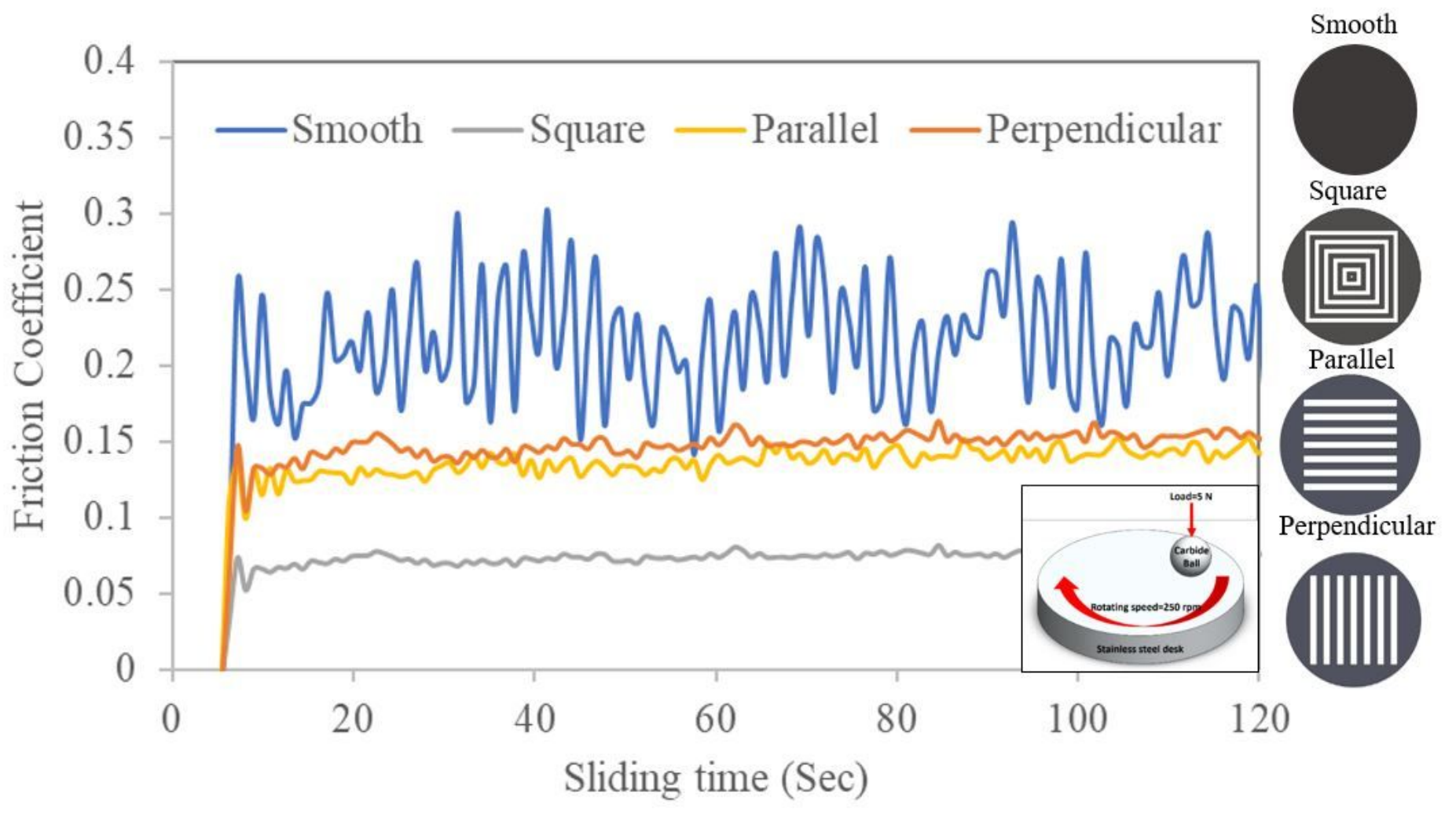

\section{Figure 9}

Variation of coefficient of friction with sliding time for smooth and textured surfaces. 


\begin{tabular}{|c|c|c|c|l|}
\hline Element & O & Fe & Cr & Others \\
\hline $\mathbf{A}$ & 20.15 & 50.13 & 20.25 & 9.47 \\
\hline $\mathbf{B}$ & 15.13 & 50.15 & 21.15 & 13.57 \\
\hline $\mathbf{C}$ & 12.12 & 40.13 & 20.12 & 27.63 \\
\hline
\end{tabular}

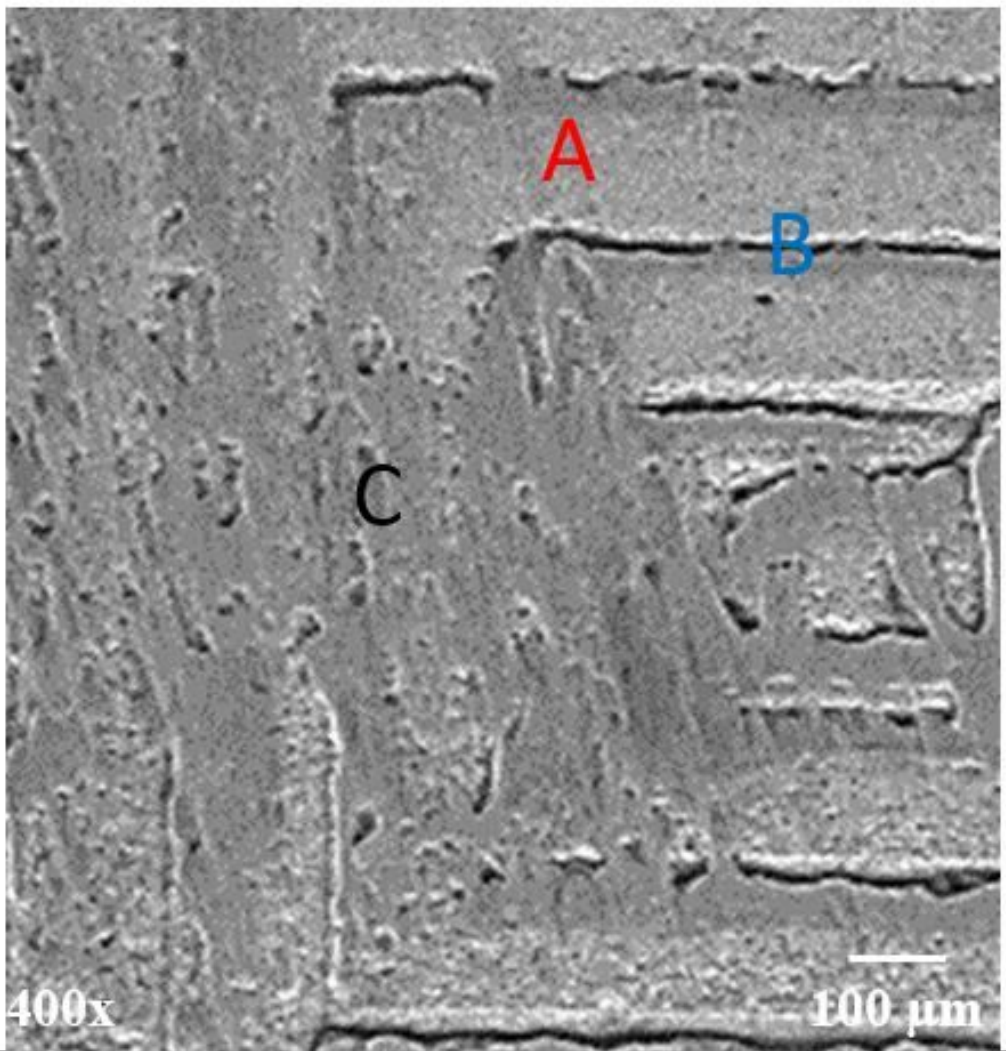

Figure 10

SEM image of worn surfaces of square surface under sliding friction and EDS analysis of points $A, B$ and C. 


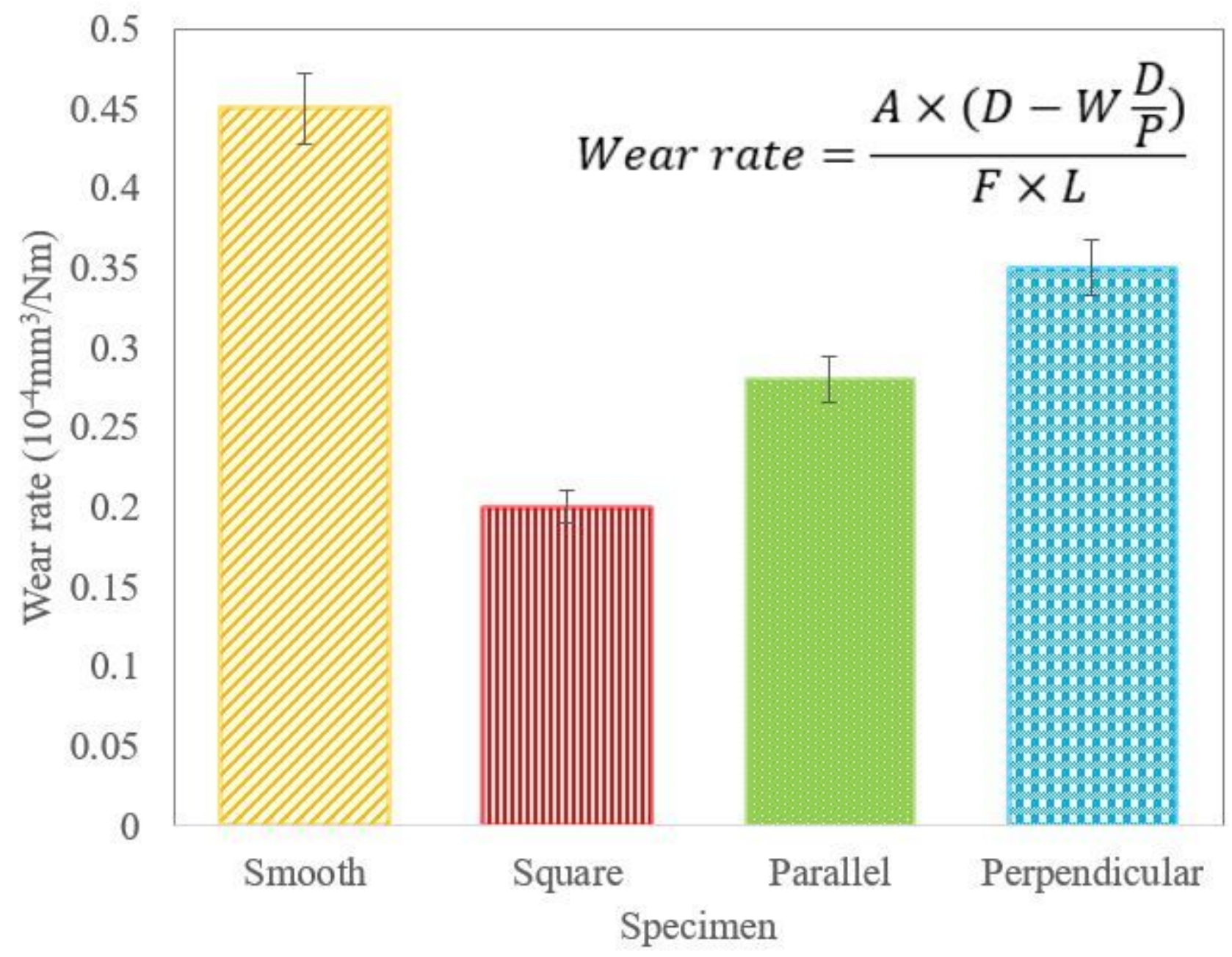

Figure 11

Wear rate of different laser textured specimens. 


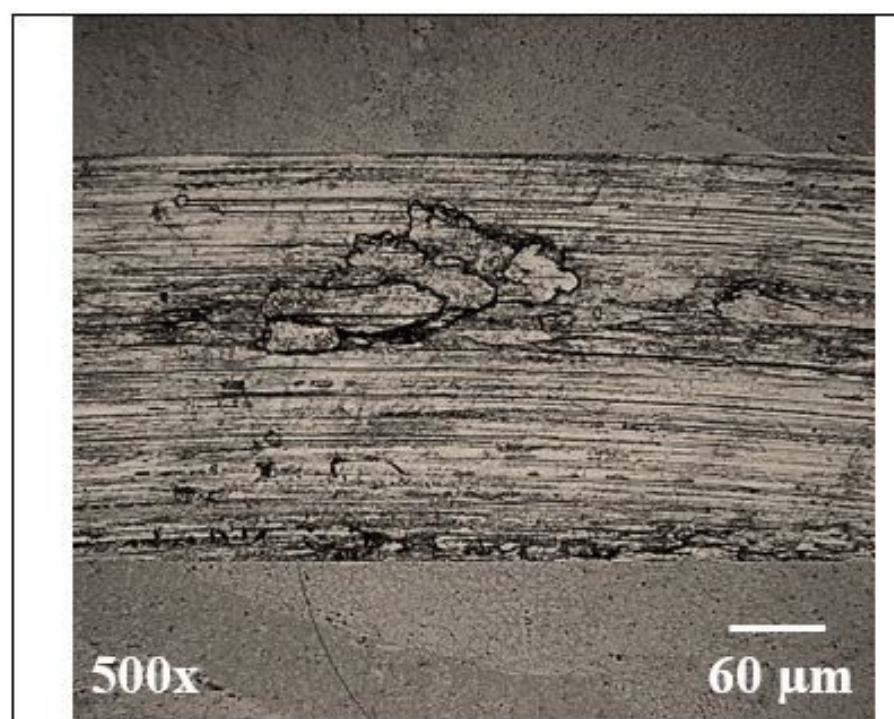

(a)

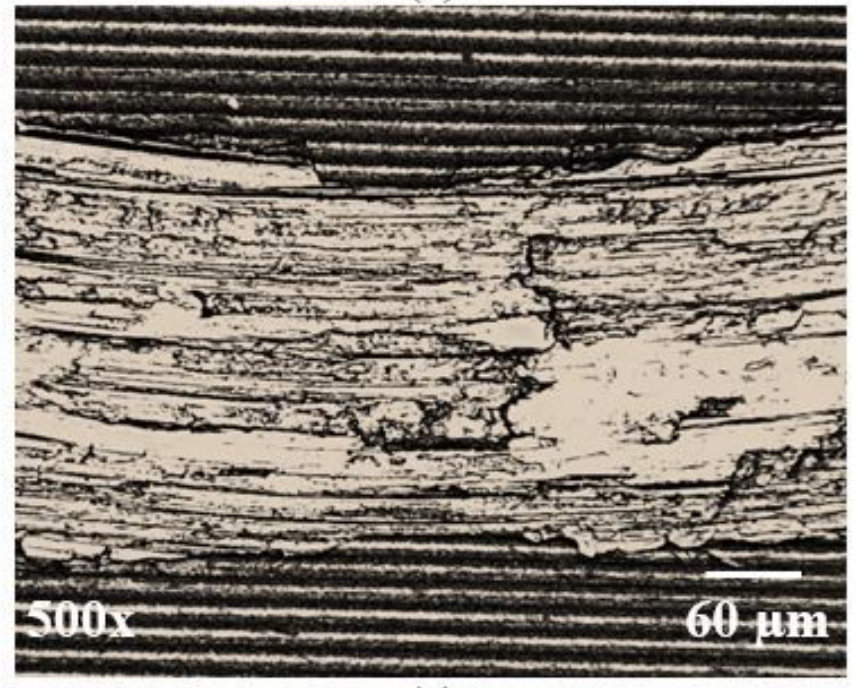

(c)

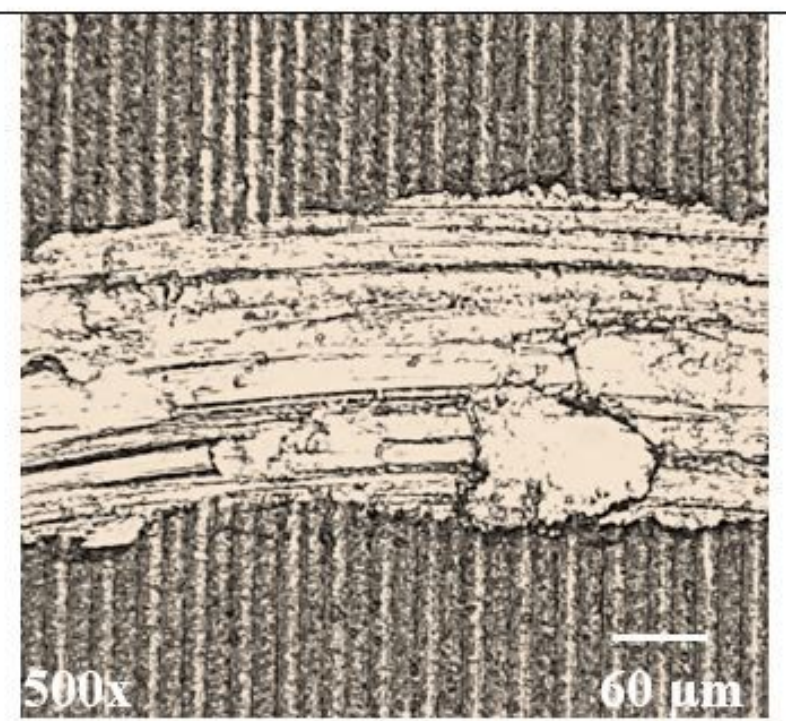

(b)

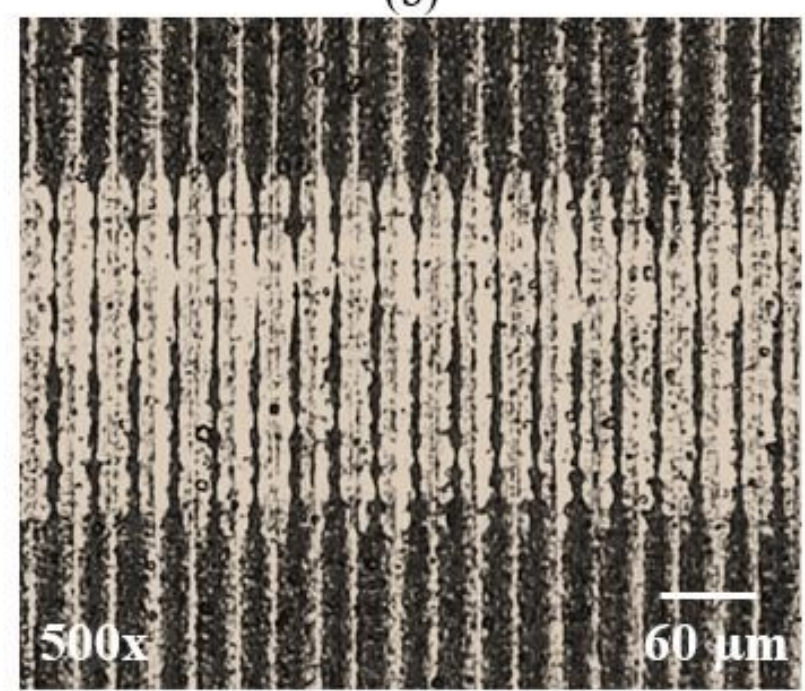

(d)

\section{Figure 12}

Optical micrographs of worn surfaces of smooth and textured samples after dry sliding friction: (a) Smooth, (b) perpendicular, (c) parallel, and (d) square surfaces. 


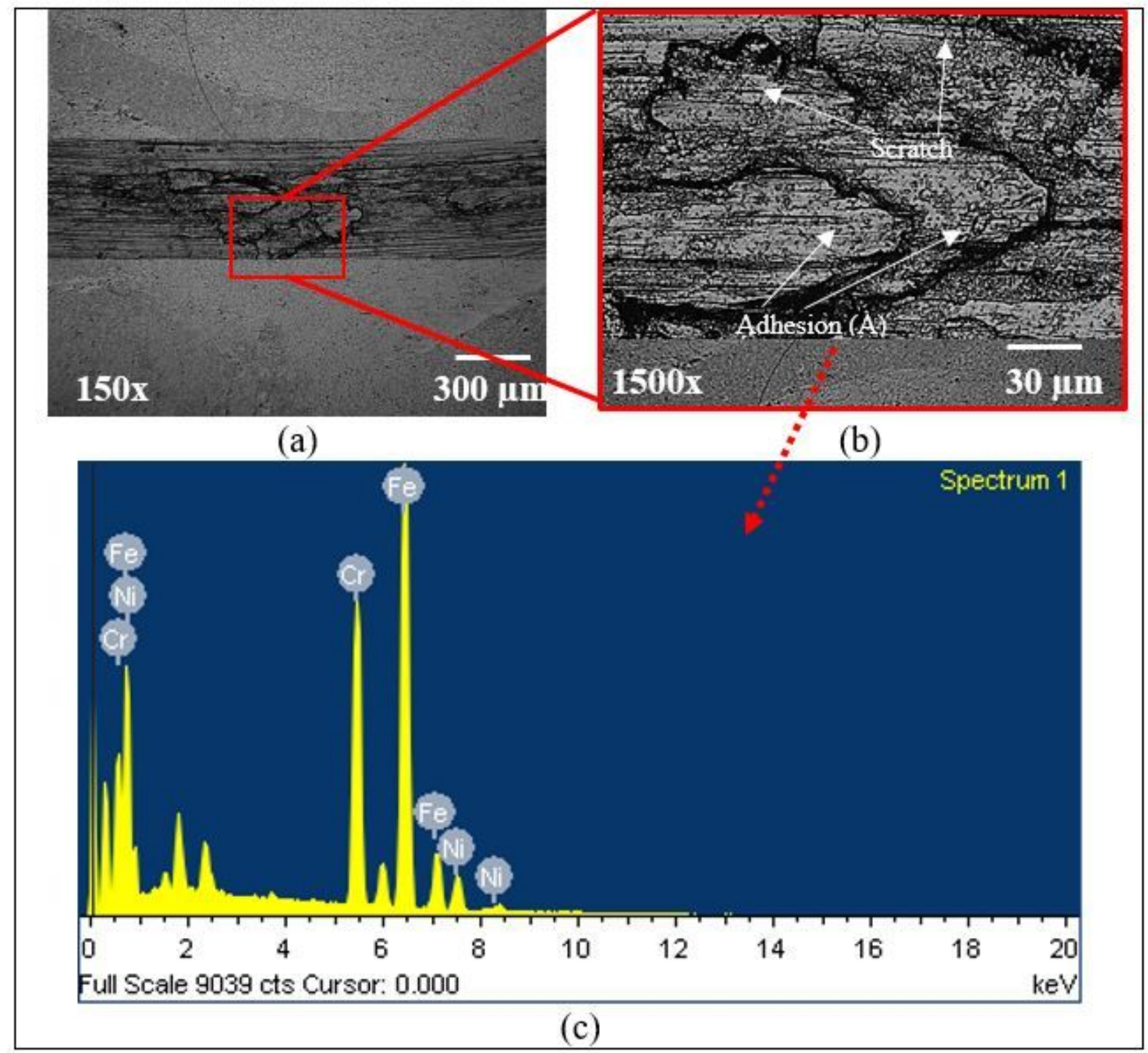

Figure 13

SEM micrographs of worn surfaces of smooth surface after dry sliding friction and EDS analysis of point A. 


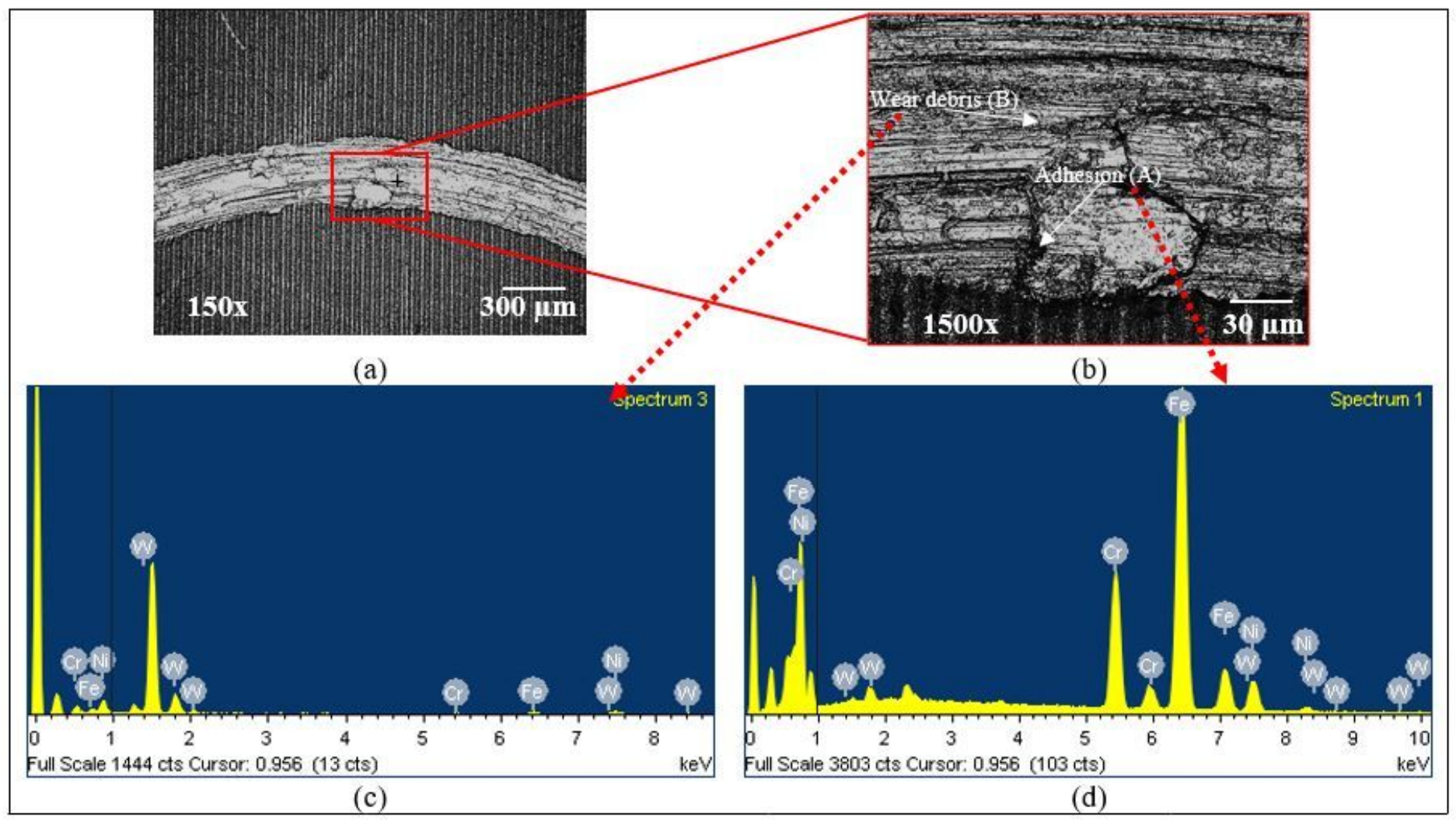

Figure 14

SEM micrographs of worn surfaces of perpindicular surface after dry sliding friction and EDS analysis of points $A$ and $B$. 


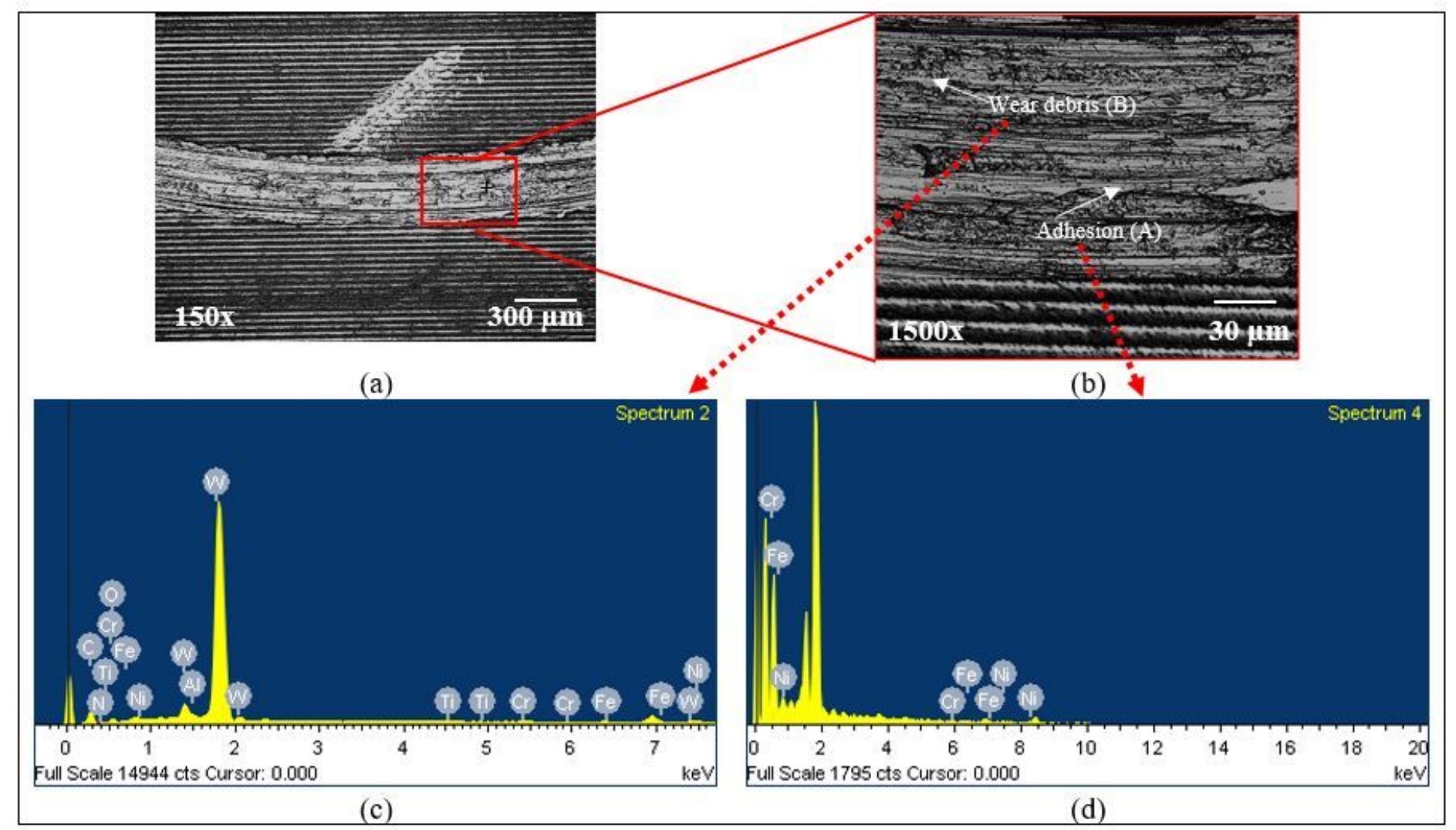

Figure 15

SEM micrographs of worn surfaces of parallel surface after dry sliding friction and EDS analysis of points $A$ and $B$. 


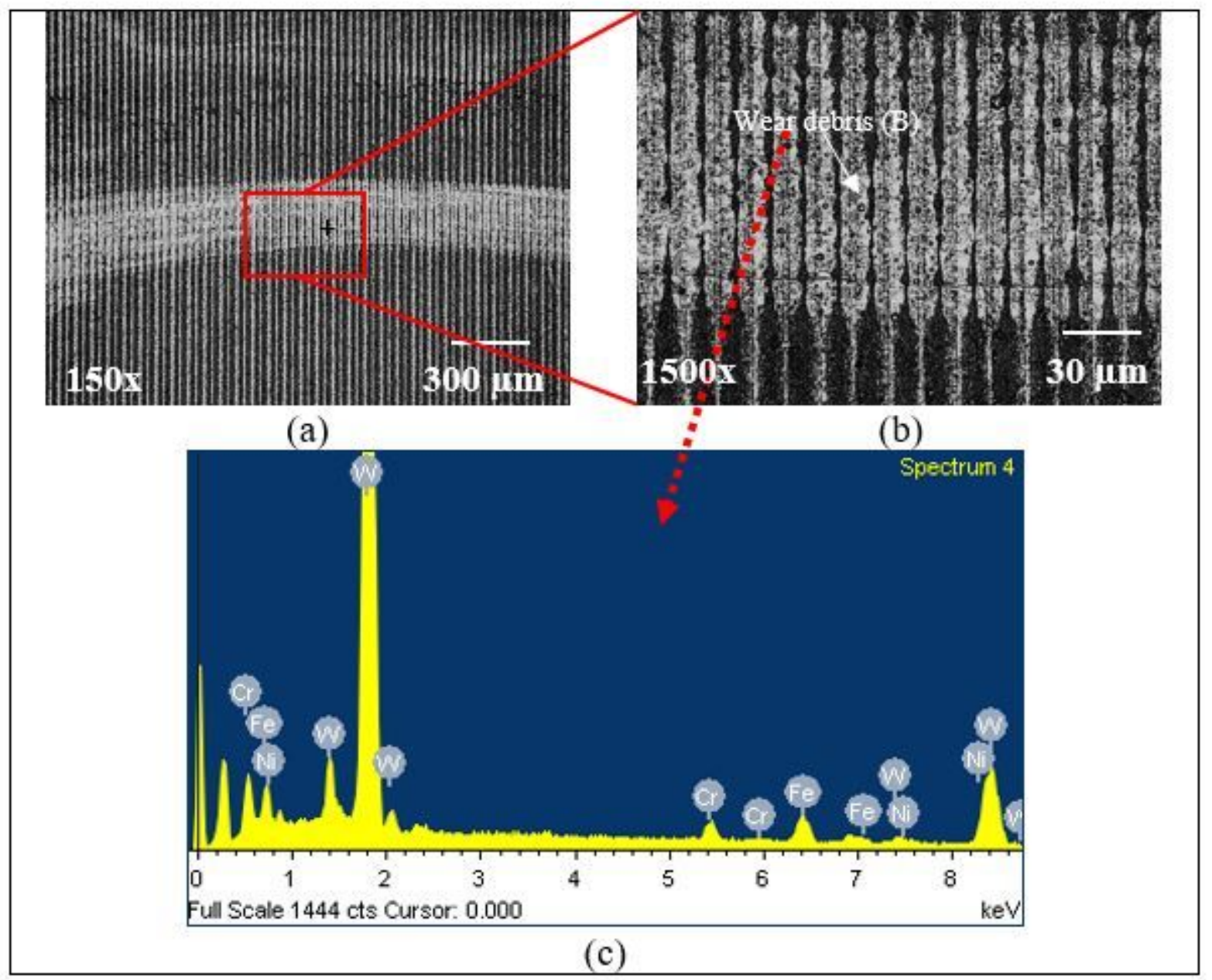

Figure 16

SEM micrographs of worn surfaces of square surface after dry sliding friction and EDS analysis of point B. 


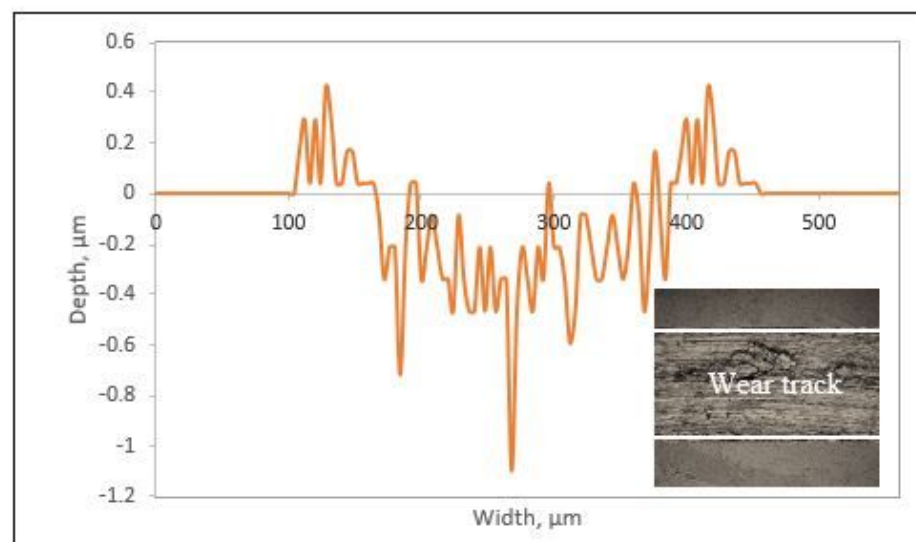

(a)

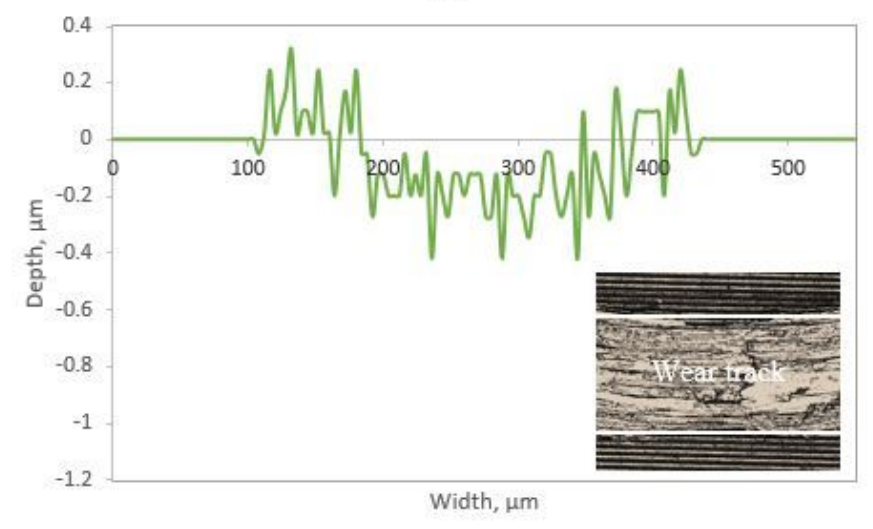

(c)

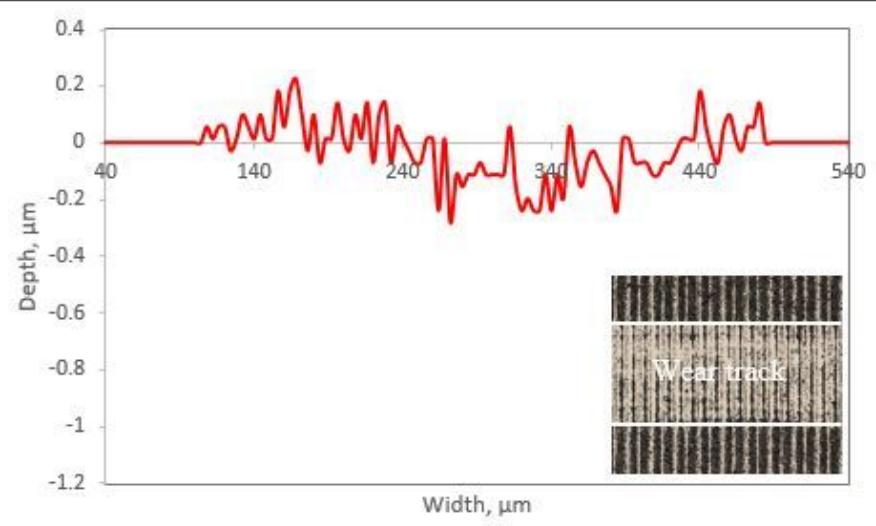

(b)

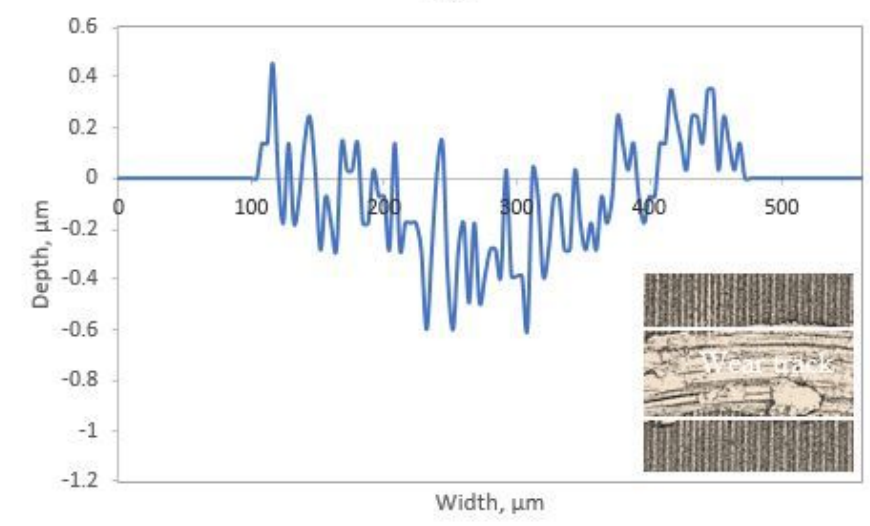

(d)

\section{Figure 17}

Profiles of the wear tracks on the samples after dry sliding friction detected by a white light interferometer: (a) smooth, (b) square, (c) parallel, and (d) perpendicular surfaces.

\section{Supplementary Files}

This is a list of supplementary files associated with this preprint. Click to download.

- Graphicalabstract.pdf 